\title{
The ant fauna of the Pilbara Bioregion, Western Australia
}

\author{
B.E. Heterick ${ }^{1}$, B. Durrant ${ }^{2}$ and N.R. Gunawardene ${ }^{1}$ \\ ${ }^{1}$ Curtin University of Technology, GPO Box U1987, Perth, Western Australia 6845, Australia. \\ Email: b.heterick@curtin.edu.au
}

${ }^{2}$ Department of Environment and Conservation, PO Box 51, Wanneroo, Western Australia 6946, Australia

\begin{abstract}
The ant fauna of the Pilbara Bioregion, which covers an area of ca. 179,000 km², is reviewed. During surveys undertaken between May 2003 and September 2006, ants were one of the taxonomic groups to receive special attention. The total number of ant species recorded from 24 survey areas was 245, and these were placed in 37 genera and 9 subfamilies. Ants recorded from single quadrats ('singletons') accounted for $18.8 \%$ of the species. The most speciose genera were Camponotus (36 spp.), Iridomyrmex (31 spp.) and Melophorus (30 spp.). Based on current knowledge, 43\% are purely Eremaean, $8 \%$ are primarily Bassian, $6 \%$ are primarily Torresian, nearly $17 \%$ occur over two of Australia's three biogeographic divisions, and $25 \%$ are widespread over all three. At a quadrat level, there was no significant correlation between richness and any environmental variable, while clustering analysis revealed weak environmental correlations with ant assemblage composition. The classification at survey area level identified six groupings of ants; three climatic variables associated with these groupings were identified, namely annual temperature, precipitation in the coldest quarter of the year and annual precipitation.
\end{abstract}

\section{INTRODUCTION}

Biodiversity surveys have become an increasingly important aspect of environmental management in Western Australia (WA). In recent years, outputs of such surveys have included databases of flora, fauna and soil type (FloraBase, etc.). These have paved the way for mapping floristically or faunistically rich areas for gazettal as conservation reserves, for identifying ecological processes important for ecosystem functioning, and for examining the effects of land use on the environment (e.g. surveys of Kimberley rainforests, Southern Carnarvon Basin, Western Australian agricultural region). Since 2003, the Pilbara Bioregion of Western Australia has been subject to a regional survey of its biodiversity (McKenzie et al. 2009). The emphasis has been on detecting broad-scale biogeographic trends in order to provide a regional framework for assessing conservation priorities. Particular attention has been paid to localised occurrences of terrestrial and aquatic invertebrates, both on the surface and in groundwater. This paper analyses and discusses the distribution of ant species in the Pilbara Bioregion.

The ant fauna of Australia has been recognised as one of the richest in the world. Shattuck (1999) recognised 1275 described Australian ant species, with the proviso that the final figure could be much higher. Currently, approximately 1365 taxon names can be obtained from the CSIRO site 'Ants Down
Under', with many recently described species not yet added to the database. In total, 710 Western Australian species and morphospecies of ants from 64 genera are recognised in the Curtin University of Technology Ant Collection.

Regional diversity patterns are quite variable, with 243 species recognised for the southern Carnarvon Basin (Gunawardene and Majer 2004) and approximately 500 species for the SouthWest Botanical Province (Heterick 2009). There is a considerable degree of overlap between the temperate and northern faunas. The ant fauna of the Kimberley and of the eastern deserts has not yet been subject to intensive survey, although small surveys have been made in particular vegetation types (Andersen and Majer 1991; Gunawardene and Majer 2004). The final species richness for the whole State of Western Australia, therefore, cannot yet be determined, but is likely to be under 1000 species. Nonetheless, this is a rich fauna, with a high degree of endemicity.

This paper documents the ant species collected in the Pilbara Bioregional Survey and augments the current knowledge of ant species diversity of WA. These results increase our understanding of broad-scale patterns of species distribution within the State and across Australia. We also present analyses of species richness, abundance and species composition in relation to regional climatic, geomorphological and vegetative patterns. 


\section{METHODS}

\section{Study area}

The Pilbara Bioregion covers ca. 179,000 km² and extends from the southern boundary of the Great Sandy Desert, east to the Robertson Range, and south-east to approximately the Tropic of Capricorn. The bioregional boundary extends north-west almost to Onslow, excluding the North West Cape, Exmouth Gulf and Barrow Island. In the broadest sense, the Pilbara bioregion is one of 13 Australian subdivisions comprising the Eremaean Province (Thackway and Cresswell 1995; Environment Australia 2000). The climate of the Pilbara is typical of arid to semi-arid areas in the southern hemisphere in having high diurnal temperatures, with maxima usually exceeding $32^{\circ} \mathrm{C}$ (occasionally exceeding $45^{\circ} \mathrm{C}$ ) in the summer months. Summer cyclonic events provide much of the approximately $300 \mathrm{~mm}$ annual average rainfall in the Fortescue, Hamersley and Roebourne subregions (May and McKenzie 2003).

The Pilbara Bioregion is divided into four subregions (Figure 1), each with distinctive landscapes (May and McKenzie 2003). The Hamersley Range subregion is characterised by two basic vegetation types-mulga (Acacia aneura) woodland over bunch grasses (Aristida spp., Enneapogon spp.) on fine-textured soils, and snappy gum (Eucalyptus leucophloia) over Triodia brizoides on skeletal soils. The Fortescue Plains subregion includes salt marsh, mulga-bunch grass and various short grass communities and also contains the northernmost occurrence of mulga. The Chichester subregion is dominated by scrub steppe on Archaean granite and basalt plains and ranges. Here, Acacia inaequilatera is the most typical shrub, growing over Triodia wiseana, a hummock grass. On the ranges, snappy gum can be found. Finally, the Roebourne subregion includes extensive dwarf shrub steppe dominated by Acacia translucens and Triodia pungens on the alluvial plains. Samphire (Tecticornia), Sporobolus grass and mangrove swamp (known as mangal) typically occur along the marine flats.

\section{Sampling strategy}

Twenty-four survey areas (Figure 1), comprising a total of 304 quadrats, were sampled. The survey areas were relatively evenly distributed throughout the study area, with 11 to 13 quadrats positioned in each area to represent different components of its geomorphic and topographic profiles. Quadrats were placed in the less disturbed patches of each habitat type, away from such areas as stock watering points. The more extensive geomorphic units in each survey area were sampled with more than one quadrat. Each quadrat was a $50 \times 50 \mathrm{~m}$ block, with a pitfall trap at each of the four corners and one in the centre. Each pitfall trap was a $2 \mathrm{~L}$ UV-stabilised plastic jar inserted into a PVC sleeve (internal diameter $125 \mathrm{~mm}$ and $250 \mathrm{~mm}$ in length) flush with the ground. During the first four months of sampling, the pitfall traps were left uncovered. Thereafter, two hoop iron stands were placed between the trap and the sleeve, holding a $200 \times 200$



Figure 1 The Pilbara bioregion with the 24 survey areas and the individual quadrats marked by symbols. The subregions are also identified. 
$\mathrm{mm}$ colorbond steel roof about 3-4 $\mathrm{cm}$ above the ground to protect the trap's contents from rainfall. A perspex ring covered in glued sand filled the gap between the jar lip and the PVC sleeve. One litre of $70 \%$ ethylene glycol (mixed with $4 \%$ formalin) was poured into the trap, which was left open for approximately 12 months.

Quadrats in the DRC, DRE, DRW, NE, NW, PE, PW, RHNC, RHNE, RHNW, WYE and WYW survey areas were sampled from July-September 2003 to September-October 2004. Sampling of 26 of these 151 quadrats continued to May 2005 due to disturbance issues during the initial sampling period. The remaining survey areas-BDRN, BDRS, MBE, MBW, OYE, OYW, PHYC, PHYE, PHYW, TCMBC, TCMBE and TCMBW-were sampled from July-October 2005 to August-September 2006. The contents of the five pitfall traps for each quadrat were pooled and preliminary taxonomic sorting was carried out. All morphospecies from each quadrat were then compared with voucher specimens of ant species in the Curtin University of Technology Ant Collection. Selected vouchers from the Pilbara Bioregional Survey have been incorporated into this collection.

A set of 19 climatic attributes (from a maximum of 35) was derived for each quadrat using BIOCLIM (Nix 1986; Houlder et al. 2001) and assessed along with 14 soil and geomorphic values (Wyroll et al. 2000) and a wide range of additional geographical and vegetative attributes (Appendix $A$ to $D$ in McKenzie et al. 2009).

\section{Numerical and statistical analysis}

A Mao Tau species accumulation curve, with ACE and ICE estimators (using Sample-based Rarefaction, EstimateS 8.0.0), was carried out to assess sampling effort and provide an estimation of total species richness for the region.

All species were categorised based on Spencer's (1896) biogeographic division of Australia into Bassian, Eyrean and Torresian faunal 'subregions'. The assignment of species among these biogeographic divisions was, at times, tentative, given the lack of knowledge for many species. These limitations were taken into account when analysing the results.

Analysis of similarity in Primer (ANOSIM and BEST) (Clarke and Gorley 2006) was used to check for significant correlations between ant richness and environmental and habitat variables. Significant inter-correlations (i.e. $r_{s}>0.7$ ) between the environmental attributes were identified using Spearman's rank order correlation coefficient.

At quadrat level, numerical procedures in the computer package PATN (Belbin 1989, 1991) were used to classify quadrats in terms of their similarities (Bray-Curtis) in species composition. Species were also clustered according to their cooccurrences at the same quadrants (Two-step).

By pooling the quadrat data for each survey area, the 24 survey areas could be classified in terms of their overall species composition. At this broader scale, the soil, topographic and vegetative variables are irrelevant as they are properties of the individual quadrats that vary greatly within each survey area, so only the geographic (latitude, longitude and distance from coast (DistCst)) and climatic variables, averaged for each survey area, could be used.

PATN-generated box and whisker plots were used to identify variables that showed differences between clusters. Differences were quantified using a permutational multiple ANOVA, in the software package PERMANOVA+ (Anderson 2005), for each of the variables, using partial sum of squares and unrestricted permutation of the data (i.e. 9999 permutations).

\section{RESULTS}

\section{Species richness}

A total of 245 ant species and morphospecies (hereafter considered as species) from 9 subfamilies and 37 genera was collected across 294 quadrats (Appendix 1). Names were assigned to 130 species (53\% of the total) with reasonable confidence. The 43 species caught at only one quadrat (i.e. 'singletons') accounted for $18.8 \%$ of the survey richness. Although 38 quadrats had singleton species, no quadrat had more than two singletons. They accounted for, at most, $12.5 \%$ of the richness at a quadrat at an average of $6.4 \%$, not including quadrats where there were no singletons. At the survey area level, all but three (WYE, PHYC and MBW) had singletons. There were no more than four singletons at any one survey area, and they never accounted for more than $5 \%$ of the richness.

Species accumulation shows a typical curve towards an asymptote (Figure 2). The mean coverage estimator of species richness based on abundance (ACE) was 280 and that based on incidence (ICE) was also 280. According to sampling effort, a further 35 species have the potential to be captured in this bioregion. This should be viewed within the context of the sampling limitations of pitfall trapping. Arboreal and solitary foraging species may be sampled ineffectively by pitfall trapping and as such could influence this estimation.

An average of 17 species (including singletons) was recorded per quadrat, with a minimum of 4 and a maximum of $42(\mathrm{SD}=6.1)$. There was an average of 76 species per survey area, with 


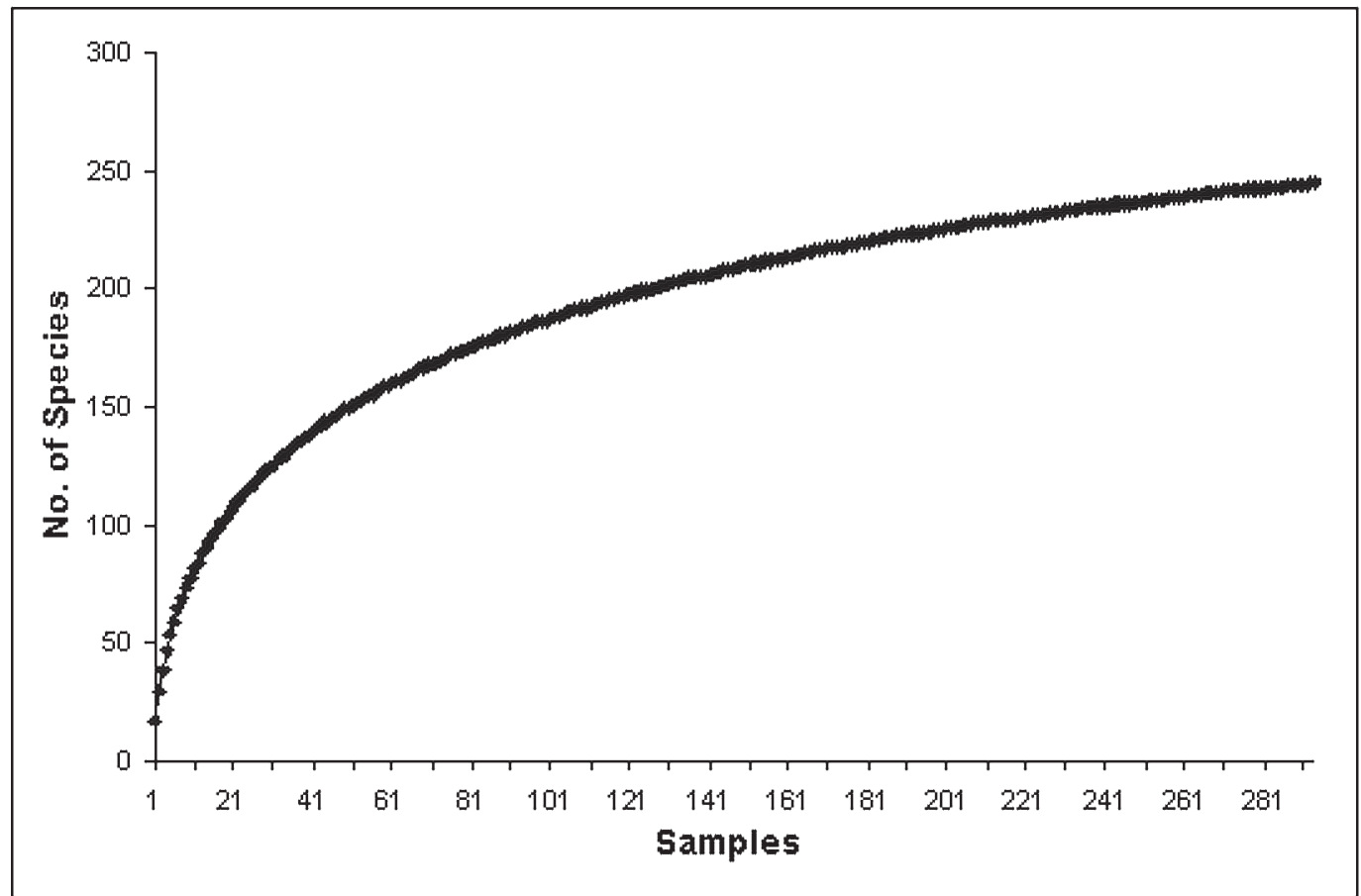

Figure 2 Incidence-based (presence/absence) species accumulation curve (ICE) of the ant fauna data using the observed number of species (Sobs Mao Tau) in EstimateS version 8.0.0 (Colwell 2006).

a minimum of 54 and a maximum of 96 (SD = 37). Individual species were found to range over an average of 21 quadrats $(1-235 ; \mathrm{SD}=36.2)$ and 7.6 survey areas $(1-24 ; \mathrm{SD}=11.4)$. There was no significant correlation between quadrat richness and any environmental variable. However, there was a significant relationship $(P=0.127)$, albeit a very weak one, between the average quadrat richness and the subregions Roebourne $(\mathrm{SD}=17.8)$ and Chichester $(\mathrm{SD}=17)$, and of $P=0.144$ between Fortescue (SD = 16.8) and Chichester $(S D=17)$.

The two survey areas richest in ants were DRW (96 spp.) in the Roebourne subregion and RHNW (94 spp.) in the Fortescue subregion; the poorest were TCMBC (59 spp.) in the Hamersley subregion and MBW (60 spp.) in the Chichester subregion (Figure 3).

The two most common ant species were Camponotus discors Forel and Monomorium disetigerum Heterick (224 quadrats). Nine of the 10 most common species were from the genera Camponotus, Iridomyrmex and Melophorus, with 36, 31 and 30 species, respectively. Thirteen of the 37 genera were represented by only a single species, and 25 contained fewer than 5 species. Only 7 genera had more than 10 species.

\section{Biogeographic distribution}

Based on current knowledge, all species were categorised in terms of their biogeographic origin as Eyrean, Torresian, Bassian or widespread.
Nearly $17 \%$ of the total species occur across two biogeographic provinces. More than $43 \%$ of the species were classified as only Eyrean, and 26\% were widespread species, occurring across all three biogeographic divisions. Only $8 \%$ and $6 \%$ of the species were primarily Bassian or Torresian, respectively. Except for species of Bassian origin, there was no difference in the regional distribution of any of these groups, i.e. they all occurred uniformly across the entire bioregion. Twenty-one of the 31 Bassian species (including 12 that also extend into the Eyrean division, and one that extends into the Torresian division) occurred almost exclusively along or south of the Fortescue River (Figure 4).

\section{Quadrat-level classification}

Singleton species, along with quadrats where sampling problems were encountered, were removed, leaving 294 quadrats and 199 species. The classification analyses did not reveal discrete clustering among either the quadrats or the species, even when common and uncommon species and widespread and localised species were analysed separately to isolate their potentially conflicting influences. When Primer was used to assess the classification results in terms of the environmental variables, Global ' $R$ ' was not significant until the data were split into more than 60 groups of quadrats. Even at that level, Global ' $R$ ' was only weakly significant. 


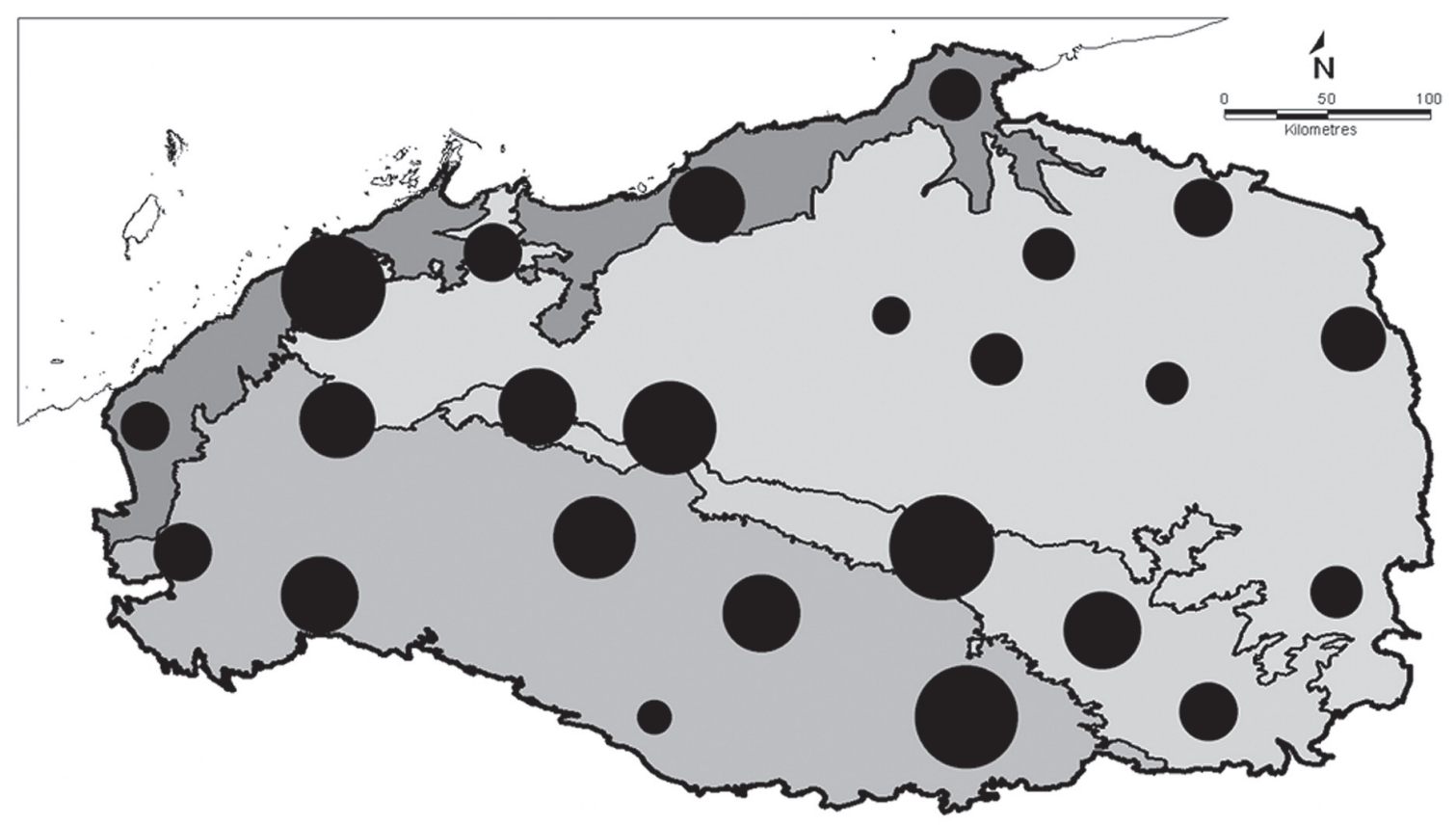

Figure 3 Survey areas described in terms of relative ant species richness. The largest circles represent the richest survey areas, the smallest circles the most depauperate sites. Survey areas falling between these two extremes are depicted proportionately in relation to their species richness.

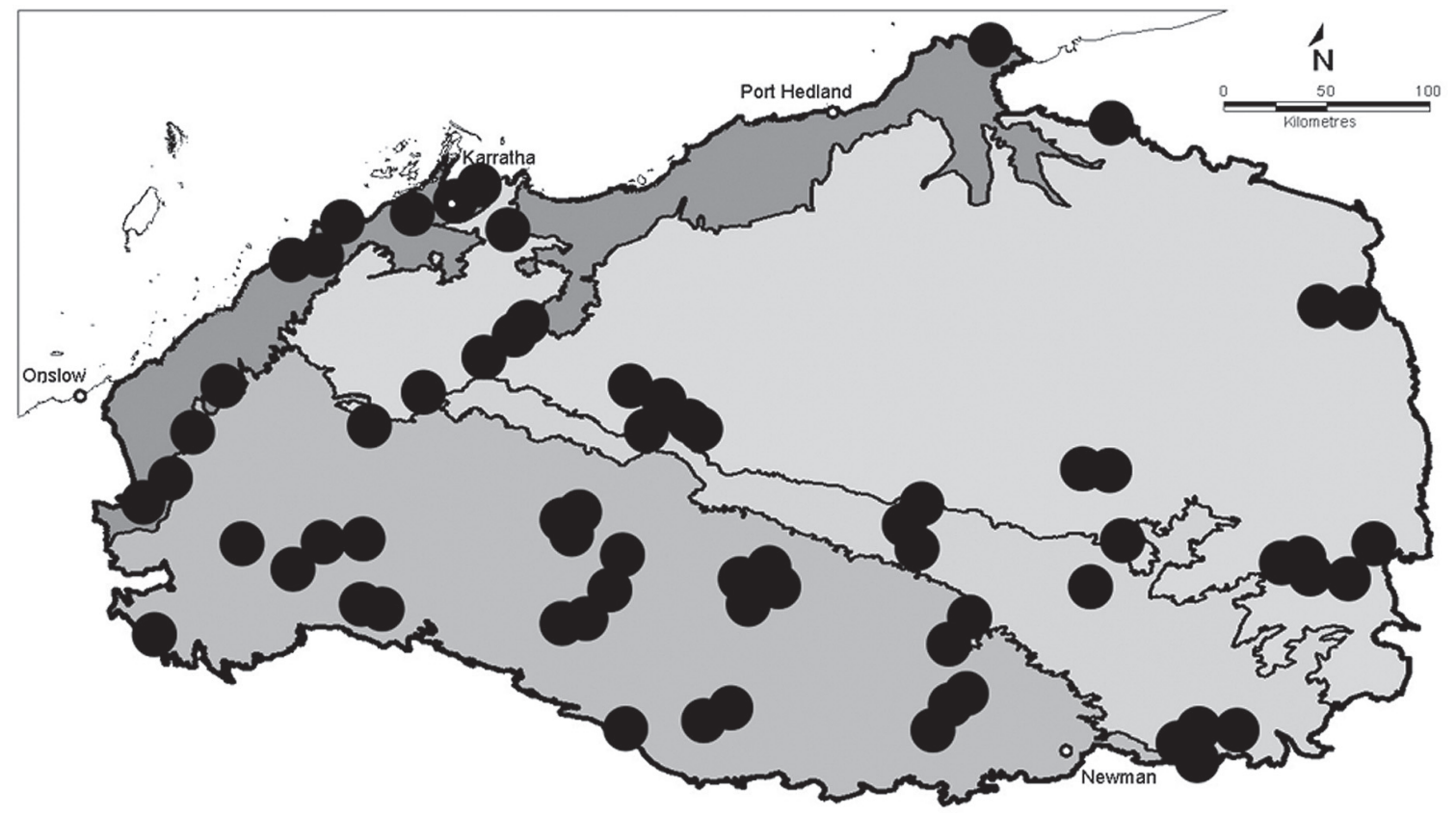

Figure 4 The distribution of species considered to be of Bassian origin. 


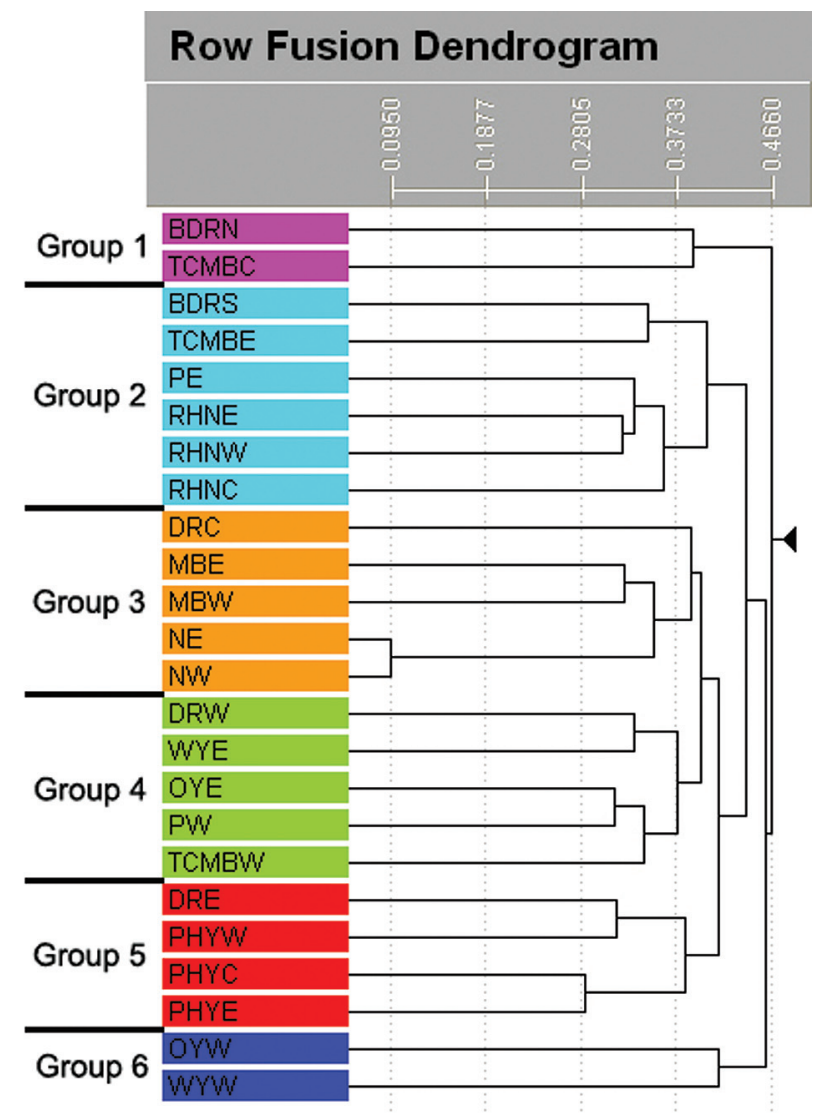

Figure 5 Dendrogram of hierarchical clustering in PATN for survey areas.

\section{Survey area level classification}

In terms of species composition, the survey area classification revealed geographically discrete clustering down to the six-group level (Figures 5 and 6). These clusters did not correspond with the subregional boundaries.

- Group 1 consists of BDRN and TCMBC, located at the periphery of the Pilbara bioregion, the former being in the south-east of the Chichester subregion, and the latter in the south-south-east of the Hamersley subregion.

- Group 2 comprises BDRS, TCMBE, PE and the three Roy Hill/Newman survey areas (i.e., RHNE, RHNW and RHNC). This group separates the two Group 1 survey areas, covers most of the Fortescue subregion and extends into the eastern Hamersley subregion.

- Group 3 immediately adjoins the Group 5 survey sites. DRC lies around Karratha, and further east lie the two Marble Bar and the two Nullagine survey areas. The latter extends to the eastern boundary of the Pilbara bioregion. DRC lies in the small area of the Chichester subregion that splits the Roebourne subregion into two. The remainder of the survey areas cover the central Chichester subregion.
- Group 4 comprises the cluster of survey areas east of Group 6 and west of Group 2. This group covers DRW on the coast. South-south-east are OYE and PW, and further in that direction lie WYE and TCMBW. This is the only group that extends across all four subregions. The bulk of the sites, however, lie in the Hamersley subregion.

- Group 5 is made up of the northernmost survey areas: i.e. DRE and the three Port Hedland/ Yarrie sites (PHYC, PHYE and PHYW). The area under these sites covers most of northern Roebourne and extends into the north-eastern Chichester subregion.

- Finally, Group 6 survey sites, i.e. OYW and WYW, are also on the periphery of the bioregion, but lying to the south-west. They are the two most westerly survey areas, and both straddle the boundary between the Hamersley and Roebourne subregions.

The PATN generated box and whisker plots (Figure 7) identified a combination of annual precipitation (Pann), annual temperature (Tann) and precipitation in the coldest quarter (PcoQ) as providing the clearest visual separation between the six groups. Table 1 reveals the PERMANOVA results for the three variables examined. Noteworthy in the table is the fact that Tann is highly correlated with Lat (0.81), and PcoQ is highly correlated with longitude $(-0.87)$.

\section{DISCUSSION}

The number of ant species collected in the Pilbara Biodiversity Survey is just over half the number of species believed to exist in the SouthWest Botanical Province. The species accumulation curve strongly suggests that at least $85 \%$ of the ant fauna has been sampled, and that the total number of species is less than 300. Although the high number of undescribed species (nearly $50 \%$ requires a certain amount of caution, recent taxonomic revisionary work suggests that the number of species recognised for an Australian ant genus approximately doubles after it has been examined in detail (Shattuck 1999). This would seem to indicate that the relative proportions of the recognised species and mostly undescribed morphospecies listed in this paper should equate reasonably closely with their actual proportions within the total ant fauna for the bioregion. The rather pessimistic views that are sometimes expressed about the progress still required to describe species among those genera with a high arid-area species component (e.g. Andersen 2007) are not supported here. Moreover, the commonly touted notion that ants in Australia are particularly diverse in arid and semi-arid regions 


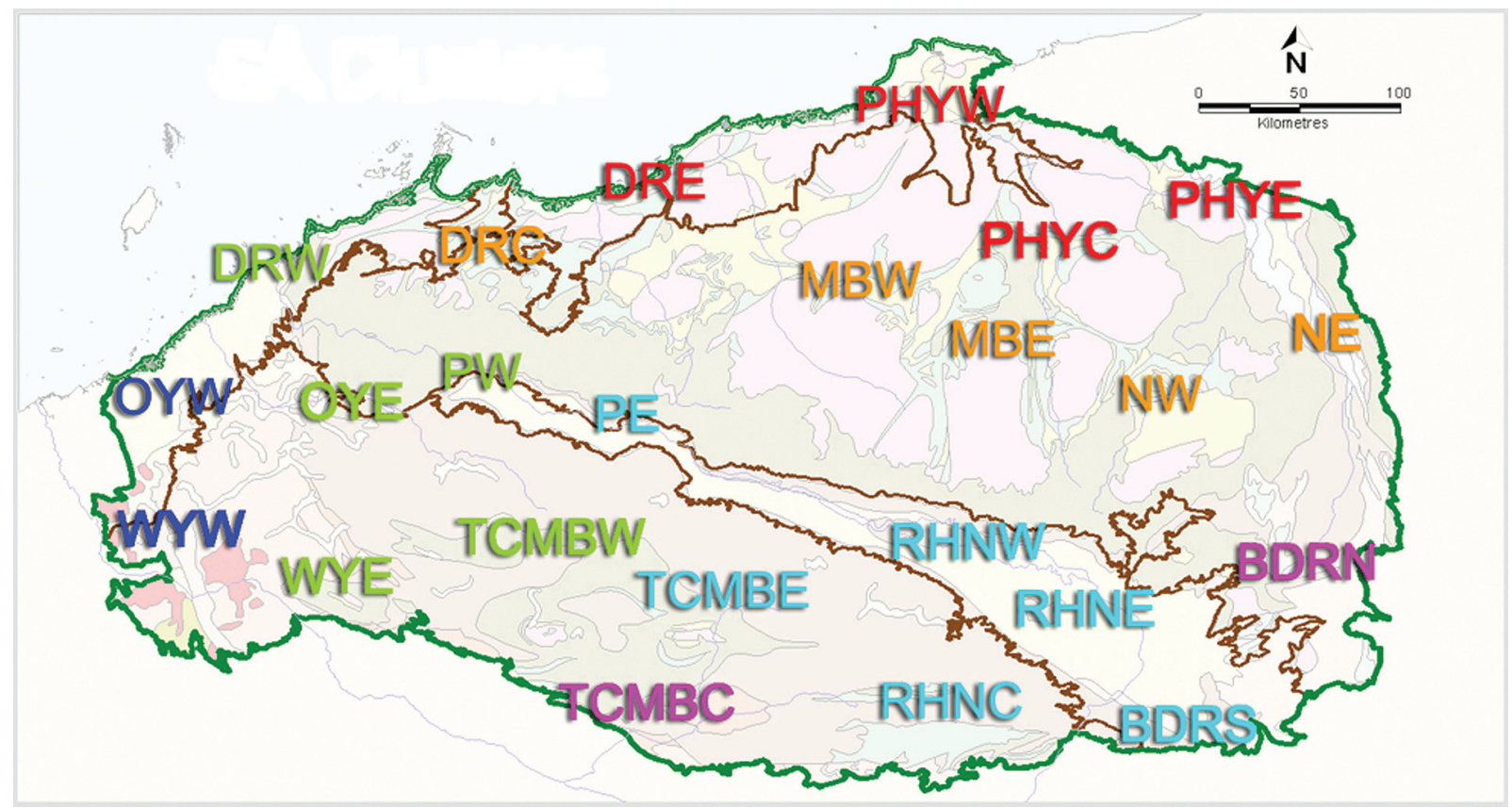

Figure 6 Survey Area clusters: pink font = Group 1; light blue font = Group 2; orange font = Group 3; green font = Group 4; red font = Group 5 and dark blue font = Group 6.

(e.g. Greenslade 1979; Andersen 2007) does not seem to hold up, at least in Western Australia.

Although terrestrial ants appear to have difficulty in highly moist substrates with regards to nest construction and maintenance, the richest Australian ant communities outside the tropical rainforests do seem to be associated with wellwatered but not overly cool environments. The finding that the Pilbara survey areas with the highest ant richness are associated with flood plains (Fortescue subregion) or are close to the coast (Roebourne subregion) is consistent with the hypothesis that ants respond to the presence of well-watered alluvial soils and the structurally and taxonomically more complex vegetation associated with them. Thus, it is no surprise that the Pann values separated the survey areas of Group 1 from the rest. Table 1 gives further support to this view, as it shows that Pann is negatively associated with longitude: the more arid Chichester subregion in the interior had the lowest richness counts (Figure 3). The richest of the Group 2 survey areas in the Fortescue subregion receives higher rainfall (Yandi Mine, slightly to the south of RHNW, received a total of $534 \mathrm{~mm}$ between 1998 and 2007, Lim and Holmes 2008). The richest of the Group 4 survey areas in the Roebourne subregion, DRW, has a lower rainfall (nearby Mardie has a mean annual rainfall of just $272 \mathrm{~mm}$, Bureau of Meteorology 2009) but this is counteracted by the close proximity of the Fortescue River. Lower rainfall is also a feature of Groups 1 (Paraburdoo, near survey area TCMBC, receives $283 \mathrm{~mm}$ annually, Bureau of
Table 1 PERMANOVA results for the three variables examined, these being the variables that provided the clearest visual separation between the six groups. Pann = annual precipitation; Tann = annual temperature and PcoQ = precipitation in the coldest quarter. Note: Tann is highly correlated with latitude (0.81), and PcoQ is highly correlated with longitude (0.87).

\begin{tabular}{c|c|c|c}
\hline & Tann & PCoQ & Pann \\
\hline Correl & Lat $\mathbf{0 . 8 1}$ & Long -0.87 & Long -0.26 \\
\hline Groups & P(perm) & P(perm) & P(perm) \\
\hline 1,2 & 0.0386 & 0.0753 & 0.0001 \\
\hline 1,3 & 0.0001 & 0.3469 & 0.0001 \\
\hline 1,4 & 0.0001 & 0.0001 & 0.0001 \\
\hline 1,5 & 0.0001 & 0.0001 & 0.0001 \\
\hline 1,6 & 0.0001 & 0.0001 & 0.0001 \\
\hline 2,3 & 0.0001 & 0.0001 & 0.5207 \\
\hline 2,4 & 0.0001 & 0.0001 & 0.3203 \\
\hline 2,5 & 0.0001 & 0.0001 & 0.7323 \\
\hline 2,6 & 0.0001 & 0.0001 & 0.6724 \\
\hline 3,4 & 0.0006 & 0.0001 & 0.0405 \\
\hline 3,5 & 0.0001 & 0.0001 & 0.569 \\
\hline 3,6 & 0.0157 & 0.0001 & 0.9416 \\
\hline 5,4 & 0.0001 & 0.0001 & 0.0917 \\
\hline 5,6 & 0.0001 & 0.0001 & 0.6553 \\
\hline 4,6 & 0.3742 & 0.0001 & 0.1458 \\
\hline & & &
\end{tabular}




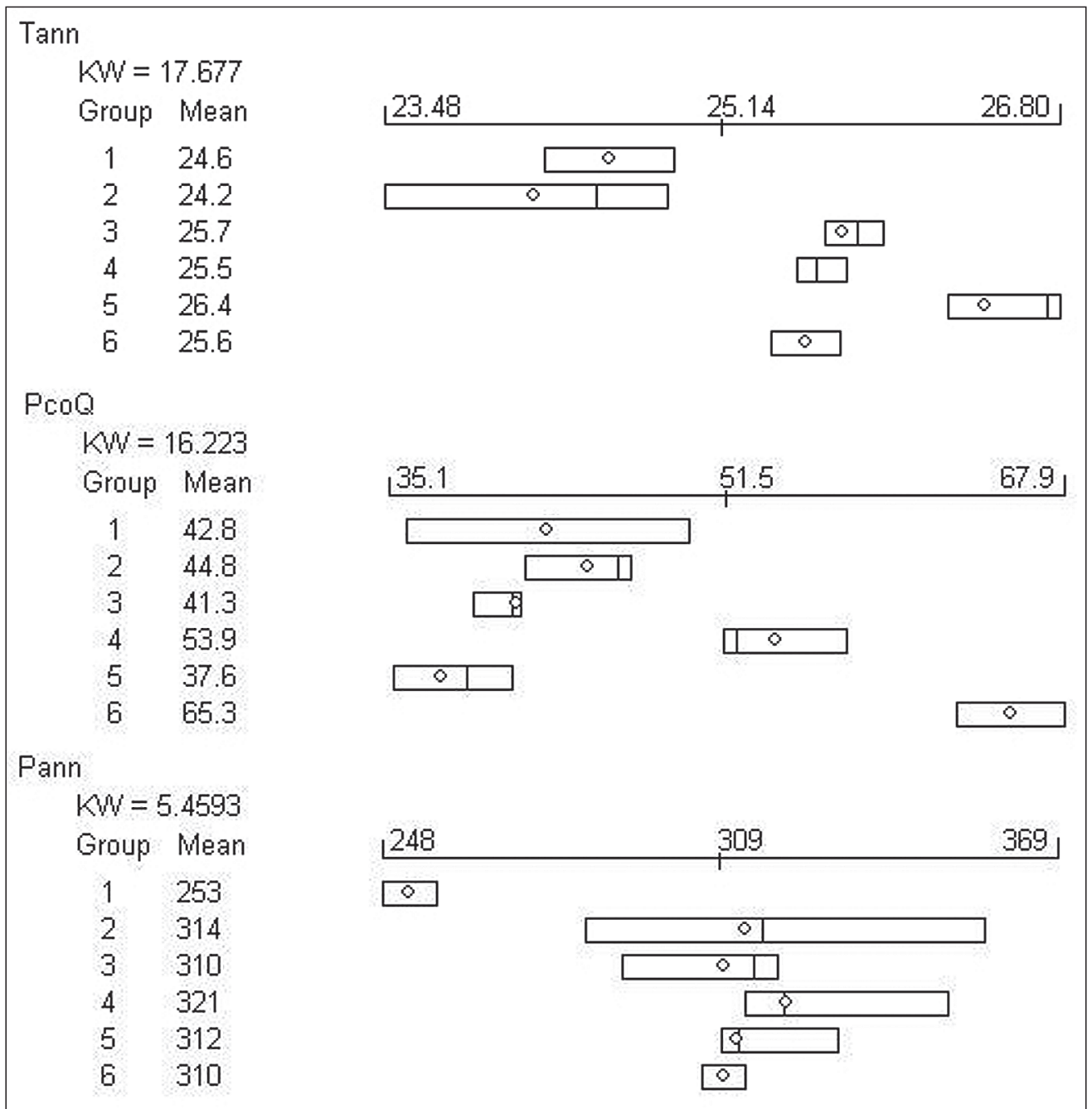

Figure $7 \quad$ PATN generated box and whisker plots for the three variables that displayed the clearest separation between clusters. Pann $=$ annual precipitation; Tann $=$ annual temperature and $\mathrm{PcoQ}=$ precipitation in the coldest quarter.

Meteorology 2009) and 3 (Wodgina mining centre, near survey area MBW, has about $314 \mathrm{~mm}$ annually, Digital Atlas Pty Limited 2009 (c). Low rainfall and the absence of a nearby large watercourse may have a direct effect on ants via the existence of harsh, unfriendly microenvironments, or indirectly by restricting potential prey or nectar sources. The low richness recorded for MBW may also be the result of fairly recent, extensive wildfire in the bioregion (Hick et al. 1998).

The differences between the ant assemblages in the survey areas are interesting. A comparison between DRW (Group 4), and MBW (Group 3), is particularly apt, since they are virtually on the same latitude, but DRW is near the coast, while MBW is $100 \mathrm{~km}$ inland. A close analysis reveals that MBW shared 52 of its 60 ant taxa $(86.7 \%)$ with DRW. Those found in MBW but not DRW belong to several genera and show no particular pattern. On the other hand, 44 ant taxa were found in DRW but not MBW. These included 10 Polyrhachis spp., which are omnivorous and nectarivorous (Shattuck 1999).
This suggests that survey area DRW has a suitably diverse flora that enables these ants to occupy a range of niches. The number of species from the genera Melophorus, Meranoplus, Monomorium, Pheidole and Tetramorium may be responding to the abundance of small seeds and possibly also arthropod carrion at DRW. All these genera include species with a strong vegetable component in their diet, e.g. ants in the Melophorus wheeleri complex are seed collectors and were found at site DRW but not MBW. Another genus found at DRW but not MBW was Cerapachys, which are specialist predators of other ants. Where abundance of suitable prey is high, Cerapachys workers, although usually sparse and rarely collected, may reach sufficient numbers to be collected in pitfall traps.

The second environmental parameter of significance was Tann. The lower annual temperatures experienced by survey areas along and south of the Fortescue River are the likely reason that ant species with a predominantly Bassian distribution may be found there. Whether the temperatures 
themselves (e.g. as an influence on foraging times or nest temperature), or their indirect effects (e.g. on nectar, honeydew or specific seed availability in the case of granivores) are what allow the species to live in the Pilbara remains to be revealed by future investigation. In the main, these taxa are not found in the deep south of the South-West Botanical Province, but are a prominent part of the ant fauna in its northern Geraldton and Murchison bioregions. Typical of such species are Calomyrmex glauerti Clark (here recorded from survey area TCMBE), Polyrhachis (Campomyrma) gravis Clark (DRE, DRW and PW) and Meranoplus cf. dimidiatus F. Smith (eight survey areas along or south of the Fortescue River).

The third variable associated with salient group characteristics was PcoQ. Precipitation in the coldest quarter of the year in Western Australia is associated with two very different climate patterns. Typically, the ant fauna of the south-west of the State has evolved with cool, wet, winters and dry, warm to hot summers. In the north, the summers tend to be hotter, and the winters drier, and ants are adapted to this climatic regime. Summer rainfall patterns tend to be a feature of coastal centres north-east of North West Cape. In the Pilbara, rainfall in winter is generally uncommon, and much of the precipitation comes from summer cyclonic or monsoonal activity. This can result in heavy, flooding rains in a short time frame. However, a bixeric rainfall distribution is evident in the western and southern Pilbara (Ruprecht 1996), and this correlates with increased ant richness in the survey area. In sites that have a secondary wet period (however ephemeral or episodic in nature) along with the usual summer rainfall, soil moisture may be maintained at a sufficiently high level to enhance plant growth at a time when plants are normally dormant or have died off. Ant activity is linked to this additional seasonal rainfall that results in increased nectar flow and insect activity, whereas ants appear to be less active in winter in areas with a winter drought. Niches for additional ant species, not normally found in summer-only rainfall regions, may thus be created.

Since ants are often used as a surrogate for other life forms (Andersen and Majer 2004; Sauberer et al. 2003; Majer et al. 2007), areas that are rich in ant species are also likely to host a good variety of other organisms. The general richness of survey areas in and around the Fortescue subregion and parts of the Roebourne subregion suggests that these areas should be considered carefully in any future deliberations on ant conservation zones in the Pilbara.

\section{ACKNOWLEDGEMENTS}

Major funding for this project was provided by the WA Department of Environment and
Conservation, with contributions from the Western Australian Museum, the Commonwealth Government (through the Natural Heritage Trust; NHT2) and Straits Resources. Substantial, inkind support was also provided by Rio Tinto Iron Ore, BHP Billiton Iron Ore and Kitchener Mining (Bamboo Creek Operation).

We gratefully acknowledge the numerous Pilbara pastoralists and Aboriginal communities for permission to visit their leases and/or land. In particular, Robyn and Tony Richardson of Mt Florance Station provided free access to their camping ground for teams to install and sample survey sites, and Rio Tinto Iron Ore provided access to subsidised housing for the first installation team while operating out of Karratha.

DEC Pilbara Region and National Park staff at Karratha and at Karijini and Millstream-Chichester National Parks provided subsidised accommodation for pit-trap installation teams and sampling teams, and the Department of Water provided access to Tabletop Hill, Harding Dam and sites along the West Pilbara water supply pipeline. Rio Tinto Iron Ore and BHP Billiton Iron Ore gave permission to enter their exploration leases and rail access roads.

We thank J. Rolfe and the installation teams for the installation and operation of the pit traps; N. Guthrie, G. Owen, J. Dunlop, E. Ladhams, S. Danti and J. Angus for assistance with sorting, data compilation and identification work; N.L. McKenzie, A.H. Burbidge and M.R. Williams for statistical advice.

\section{REFERENCES}

Andersen, A.N. (2000). The ants of northern Australia: a guide to the monsoonal fauna. CSIRO Publishing: Melbourne, Australia.

Andersen, A.N. (2007). Ant diversity in arid Australia: a systematic overview (pp 19-51). In: Snelling, R.R., Fisher, B.L. and Ward, P.S. (eds), Advances in ant systematics (Hymenoptera: Formicidae): homage to E. O. Wilson -50 years of contributions. Memoirs of the American Entomological Institute $\mathbf{8 0 .}$.

Andersen, A.N. and Majer, J.D. (1991). The structure and biogeography of rainforest ant communities in the Kimberley region of northwestern Australia (pp 333346). In: McKenzie, N.L., Johnston, R.B. and Kendrick, P.G. (eds), Kimberley rainforests of Australia. Surrey Beatty and Sons: Chipping Norton, Australia.

Andersen, A.N. and Majer, J.D. (2004). Ants show the way down under: invertebrates as bioindicators in land management. Frontiers in Ecology and the Environment 2: 291-298.

Anderson, M.J. (2005). PERMANOVA. University of Auckland, http://www.stat.auckland.ac.nz/ mja/ Programs.htm.

Belbin, L. (1989). PATN-pattern analysis package, users guide and technical reference. CSIRO Division of Wildlife and Ecology: Canberra, Australia. 
Belbin, L. (1991). The analysis of pattern in bio-survey data (pp 179-190). In: Margules, C.R. and Austin, M.P. (eds), Nature conservation: cost effective biological surveys and data analysis. CSIRO: [East Melbourne], Australia.

Bolton, B. (2000). The ant tribe Dacetini, with a revision of the Strumigenys species of the Malagasy Region by Brian L. Fisher, and a revision of the Austral epopostrumiform genera by Steven O. Shattuck. Memoirs of the American Entomological Institute 65: 30-67.

Bolton, B. (2007). Taxonomy of the dolichoderine ant genus Technomyrmex Mayr (Hymenoptera: Formicidae) based on the worker cast. Contributions of the American Entomological Institute 35: 1-150.

Bureau of Meteorology (2009). http://www.bom.gov.au [Accessed 3 March 2009].

Clarke, K.R. and Gorley, R.N. (2006). PRIMER v6: user manual/tutorial. PRIMER-E: Plymouth, U.S.A.

Colwell, R.K. (1994-2004). EstimateS: statistical estimation of species richness and shared species from samples. http:/ /viceroy.eeb.uconn.edu/estimates.

CSIRO (2009). Ants down under. http:/ / anic.ento.csiro.au/ ants / [Accessed 3 March 2009].

Digital Atlas Pty Limited (2009). http://maps.bonzle. com/c/a [Accessed 27 January 2009].

Environment Australia (2000). Revision of the Interim Biogeographic Regionalisation of Australia (IBRA) and the development of version 5.1. Summary Report. Department of Environment and Heritage: Canberra, Australia.

Greenslade, P.J.M. (1979). A guide to the ants of South Australia. South Australian Museum special education bulletin series: Adelaide, Australia.

Gunawardene, N. and Majer, J.D. (2004). Ants of the southern Carnarvon Basin, Western Australia: an investigation into patterns of association. Records of the Western Australian Museum 22: 219-239.

Heterick, B. (2001). Revision of the Australian ants of the genus Monomorium (Hymenoptera: Formicidae). Invertebrate Taxonomy 15: 353-459.

Heterick, B.E. (2003). Two new Australian Monomorium Mayr (Hymenoptera: Formicidae), including a highly distinctive species. Australian Journal of Entomology 42: 249-253.

Heterick, B.E. (2009). A guide to the ants of South-western Australia. Records of the Western Australian Museum, Supplement 76: 1-206

Hick, P., Caccetta, M. and Corner, R. (1998). An assessment of vegetation condition and monitoring strategy for Hamersley Iron's Central Pilbara Railway (CPR) through Karijini National Park using remotely-sensed and ancillary data. CSIRO Industry Report. http://www.per.dem. csiro.au/ [Accessed 27 January 2009].

Houlder, D., Hutchinson, M., Nix, H. and McMahon, J. (2001). ANUCLIM. Centre for Resource and Environmental Studies: Canberra, Australia.

LaPolla, J.S. (2004). Acropyga (Hymenoptera: Formicidae) of the World. Contributions of the American Entomological Institute 33: 1-130.

Lim, E. and Holmes, D. (2008). The moving finger writes the value of hydrographs in numerical modelling. http:/ / www.imwa.info/docs/imwa_2008/ [Accessed 27 January 2009].
McKenzie, N.L., van Leeuwen, S. and Pinder, A.M. (2009). Introduction to the Pilbara biodiversity survey, 2002-2007. Records of the Western Australian Museum, Supplement 78:1-78.

Majer, J.D., Orabi, G. and Bisevac, L. (2007). Ants (Hymenoptera: Formicidae) pass the bioindicator scorecard. Myrmecological Notes 10: 69-76.

May, J.E. and McKenzie, N.L. (2003) (eds). A biodiversity audit of Western Australia's 53 biogeographical subregions in 2002. Department of Conservation and Land Management: Kensington, Australia.

Nix, H. (1986). A biogeographic analysis of Australian Elapid snakes (pp 4-10). In: Longmore, R. (ed.), Snakes: atlas of elapid snakes of Australia: Bureau of Flora and Fauna: Canberra, Australia.

Ogata, K. and Taylor, R.W. (1991). Ants of the genus Myrmecia Fabricius: a preliminary review and key to the named species (Hymenoptera: Formicidae: Myrmeciinae). Journal of Natural History 25: 1623-1673.

Ruprecht, I. (1996). Arid zone hydrology: Pilbara region of Western Australia (pp 301-305). In: Proceedings of the 23rd Hydrology and Water Resources Symposium, 21-24 May 1996, Hobart, Australia.

Sauberer, N., Zulka, K.-P., Abensperg-Traun, M., Berg, H.M., Bieringer, G., Milasowszky, N., Moser, D., Plutzar, C., Pollheimer, M., Storch, C., Tröstl, R., Zechmeister, H.G. and Grabherr, G. (2004). Surrogate taxa for biodiversity in agricultural landscapes of eastern Austria. Biological Conservation 117: 181-190.

Shattuck, S.O. (1999). Australian ants: their biology and identification. CSIRO Publishing: Collingwood, Australia.

Shattuck, S.O. (2006). Australian species of the ant genus Diacamma (Hymenoptera: Formicidae). Myrmecologische Nachrichten 8: 13-19.

Shattuck, S.O. (2007). New species of Myrmicine ants from Western Australia (Hymenoptera: Formicidae). Zootaxa 1661: 47-53.

Shattuck, S.O. (2008). Australian ants of the genus Aphaenogaster (Hymenoptera: Formicidae). Zootaxa 1677: 25-45.

Shattuck, S.O. and Barnett, N.J. (2007). Revision of the ant genus Mayriella (pp 437-458). In: Snelling, R.R., Fisher , B.L. and Ward, P.S. (eds), Advances in ant systematics (Hymenoptera: Formicidae): homage to E. O. Wilson - 50 years of contributions. Memoirs of the American Entomological Institute $\mathbf{8 0 .}$.

Shire of Ashburton (2006). http://www.ashburton. wa.gov.au/ [Accessed 27 January 2009].

Spencer, W.B. (1896). Summary of the zoological, botanical and geological results of the expedition. Report on the work of the Horn Expedition to Central Australia. Dulau: London, U.K.

Taylor, R.W. (1983). Descriptive taxonomy: past, present, and future (pp 3-134). In: Highley, E. and Taylor, R.W. (eds). Australian systematic entomology: a bicentenary perspective. CSIRO: Canberra, Australia.

Thackwell, R. and Cresswell, I.D. (1995). An Interim Biogeographic Regionalisation for Australia: A framework for setting priorities in the national reserves system, Version 4.0. Australian Nature Conservation Agency: Canberra, Australia. 
Ward, P.S. (2001). Taxonomy, phylogeny and biogeography of the ant genus Tetraponera (Hymenoptera: Formicidae) in the Oriental and Australian regions. Invertebrate Taxonomy 15: 589-665.

Wikipedia. http://en.wikipedia.org/wiki/Pilbara [Accessed 27 January 2009].
Wyroll, K., Dong, B. and Valdes, P. (2000). On the position of southern hemisphere westerlies at the Last Glacial Maximum: an outline of AGCM simulation results and evaluation of their implications. Quaternary Science Reviews 19: 881-898.

\section{APPENDIX 1}

Table showing all ant species collected at the 294 quadrats in the Pilbara bioregion. Singleton species are highlighted in grey. Table data are presence-absence, presence being indicated by ' 1 '.

See CD inside the back cover, or visit:

http://www.museum.wa.gov.au/research/records-supplements/attachments 